\title{
EU CONHEÇO O MEU LUGAR DE VIVÊNCIA? UMA PROPOSTA DIDÁTICO-PEDAGÓGICA A PARTIR DA PLATAFORMA IBGE CIDADES
}

\author{
Do I know my place of living experience? A teaching-pedagogical proposal from \\ the IBGE CIDADES platform
}
¿Conozco a mi lugar de vivencia? Una propuesta didáctico-pedagogica desde la plataforma IBGE Ciudades

\author{
Joseane Gomes de Araújo * \\ Humberto Cordeiro Araujo Maia ** \\ * Geografia com enfâse na educação geográfica, Universidade Estadual Paulista (UNESP) \\ - jgajujuba@yahoo.com.br \\ ** Doutorando em Geografia, Universidade Estadual de Santa Cruz (Uesc) \\ - hcamaia@uesc.br
}

Recebido em 20/10/2019. Aceito para publicação em 27/01/2020.

Versão online publicada em 09/03/2020 (http://seer.ufrgs.br/paraonde)

Resumo:

Neste artigo, apresenta-se uma proposta didático-pedagógica que tem por objetivo acessibilizar aos alunos o conhecimento sobre as múltiplas dimensões e noções geográficas do lugar de vivência a partir das representações disponíveis na plataforma IBGE Cidades, na rede social "Instagram" e/ou por meio de outras linguagens. Destaca-se, assim, que a presente proposição emerge no contexto da Geografia escolar e do Ensino de Geografia como uma estratégia para atender às atuais demandas da cultura escolar no conjunto das Tecnologias Digitais da Informação e Comunicação (TDIC's). Para compreender tais questões, desenvolver-se-á uma análise bibliográfica e teórica sobre a temática, através de problematizações e inquietações que surgem das práticas dos professores da educação básica e também da educação superior. Em seguida, apresentar-se-á a elaboração da proposição pedagógica. Compreende-se, portanto, que o uso das TDIC's no ensino de Geografia, atrelado ao uso da rede social "Instagram" e/ou outras linguagens, pode ser considerado um importante dispositivo de ensino e aprendizagem das temáticas vinculadas ao lugar de vivência, possibilitando, consequentemente, o desenvolvimento do raciocínio geográfico.

Palavras-chave: Ensino de Geografia. Tecnologias Digitais da Informação e Comunicação. Instagram. IBGE Cidades. Lugar de Vivência.

\footnotetext{
Abstract:

This paper presents a didactic-pedagogical proposal to provide students with knowledge about the multiple dimensions and geographical notions of the place of living experience from the representations available on the IBGE Cidades platform, on the social network "Instagram" and/or through other languages. It stands out, therefore, that the present proposition emerges in the context of school geography and geography teaching as a strategy to meet the current demands of school culture in the set of Digital Information and Communication
} 
Technologies (DICT). In order to deal these issues, a bibliographical and theoretical analysis about the theme will be developed, through problematizations and concerns that arising from the practices of teachers of basic education and also of higher education. Then, it will be presented an elaboration of the pedagogical proposal. It is therefore understandable that the use of DICT in the geography teaching, linked to the use of the social network "Instagram", it can be considered an important teaching and learning device of the themes related to the place of living experience, thus enabling the development of geographical reasoning.

Key-words:Geography Teaching. Digital Information and Communication Technologies. Instagram. IBGE Cidades. Place of Living Experience.

\begin{abstract}
Resumen:
En esto artículo se presenta una propuesta didáctico-pedagógica que tiene como objetivo proporcionar a los alumnos conocimientos sobre las múltiples dimensiones y nociones geográficas del lugar de vivencia a partir de las representaciones disponibles en la plataforma IBGE Ciudades, en la red social "Instagram" y / o a través de otras lenguajes. Por lo tanto, esta propuesta surge en el contexto de la Geografía escolar y la enseñanza de la Geografía como una estrategia para satisfacer las demandas actuales de la cultura escolar en el conjunto de las Tecnologías Digitales de Información y Comunicación (TDIC). Para comprender estos temas, se desarrollará un análisis bibliográfico y teórico del tema a través de las problematizaciones y preocupaciones que surgen de las prácticas de los maestros de educación básica y también de la educación superior. Luego, se presentará la elaboración de la propuesta pedagógica. Por lo tanto, se entiende que el uso de las TIC en la enseñanza de la Geografía, vinculado al uso de la red social "Instagram" y / u otras lenguajes, puede considerarse un dispositivo importante para enseñar y aprender los temas relacionados con el lugar de la vivencia, permitiendo, así, el desarrollo del raciocinio geográfico.
\end{abstract}

Palabras-clave: Enseñanza de Geografía. Tecnologías Digitales de la Información y Comunicación. Instagram. IBGE Ciudades. Lugar de vivencia.

\title{
1. Introdução
}

No atual momento vivenciado pelos brasileiros, no que se refere à instabilidade política que ameaça a nação, são inúmeras as tentativas de minimizar a construção da autonomia crítica e política dos sujeitos, inclusive no espaço escolar por meio das "reformas" curriculares que objetivam homogeneizar o conhecimento e, ao mesmo tempo, engendrar a invisibilidade de algumas ciências e o deslocamento dos estudos do espaço vivido.

Atravessamos momentos obscuros, em que predomina uma evidente tendência de excluir do currículo escolar conteúdos que possibilitem a práxis social a partir da reflexão-ação-reflexão. Assim, podemos destacar algumas medidas - que não são objetos de análise no presente texto, mas que servem para contextualizar os sucessivos golpes, nem sempre visíveis, no contexto educacional -, como, por exemplo, a proposta da Base Nacional Comum Curricular (BNCC) (BRASIL, 2018) e a Reforma do Ensino Médio que, a partir de uma medida provisória, miniminiza a relevância da Geografia, dentre outros componentes curriculares. Nesse contexto, incluímos, entre as perdas e invisibilizações, as questões vinculadas ao espaço de vivência, suas composições e contradições. 
Dessa forma, urge debatermos, incessantemente, questões que direcionem a reflexão de práticas docentes, para que os espaços que ainda possam ser utilizados pelos professores de Geografia sejam usados de forma efetiva, objetivando uma análise fundamentada e crítica em torno do espaço geográfico, compreendido em sua amplitude, para que então possa ser praticado o verdadeiro objetivo de ensinar e aprender Geografia, inclusive na formação política e crítica dos estudantes. Essas considerações dialogam com a perspectiva freiriana quando esta ressalta que

[...] ninguém pode estar no mundo, com o mundo e com os outros de forma neutra. Não posso estar no mundo de luvas nas mãos constatando apenas. A acomodação em mim é apenas caminho para a inserção que implica decisão, escolha, intervenção na realidade. (FREIRE, 2015, p. 75).

Para tanto, sabemos que o momento técnico, científico e informacional que atravessa o tempo vivido mudou a concepção do próprio espaço, o que, por conseguinte, muda o modo de vida de parte da sociedade e chega diretamente na escola. A globalização como fenômeno reflete na forma de analisar e de viver o mundo, e chega também no espaço escolar, através de instrumentos que podem ser utilizados pelos professores e alunos, mas sobretudo no que se refere ao acesso às informações nas mais diversas escalas de análise geográfica.

Desse modo, a valorização do conhecimento cotidiano do lugar de vivência, por parte do professor, com foco na mediação para a formação de novas noções e conceitos, possibilita que o estudante compreenda o seu papel social, ao invés de ser um mero especulador do saber sobre seu lugar de vivência e os diferentes contextos da realidade.

Para compreender tais situações, neste artigo, resultante de atividade vinculada ao componente curricular Cartografia escolar e geotecnologias no ensino de Geografia, do Programa de Pós-Graduação em Geografia, Linha 02 - Cartografia e Cartografia escolar, da Universidade Estadual Paulista Júlio de Mesquita Filho (Unesp), Campus de Rio Claro, apresentamos algumas considerações sobre as possibilidades de aprender e olhar geograficamente 0 lugar de vivência, para entender a ótica da sua dinâmica. Assim, este trabalho está dividido em três partes, sendo elas:

O estudo do lugar de vivência no ensino de Geografia. Em que desenvolvemos um debate conceitual acerca do lugar de vivência a partir da cidade e do urbano, e seus rebatimentos na educação geográfica, considerando, para tanto, as políticas educacionais.

Os recursos tecnológicos/cartográficos na construção de temas, noções e conceitos geográficos do/no lugar. Neste item, apontamos as potencialidades e possíveis limitações do uso das TDIC's no desenvolvimento de práticas pedagógicas no ensino de Geografia, inclusive destacando relações com a linguagem cartográfica. Discutimos também sobre os reflexos desse cenário na prática docente direcionada à Geografia.

Uma proposta didático-pedagógica para o estudo do lugar de vivência

ParaOnde!?, Porto Alegre, v.13, n.1, p. 59-76, 2020. http://seer.ufrgs.br/paraonde 
a partir do uso do "Instagram" e/ou outras linguagens. Por fim, apresentamos uma proposta tomando por base informações disponibilizadas pelo site do IBGE Cidades, sobretudo a partir da linguagem cartográfica, do uso da rede social, cartazes impressos, slides, acesso online e jogo quiz. Esta proposta ainda não foi aplicada, mas pensada e estruturada a partir de questões de pesquisa voltadas ao tema na perspectiva da educação geográfica e ao uso das diferentes linguagens.

Finalizamos este trabalho com reflexões que evidenciam a potencialidade dos estudos geográficos a partir das tecnologias digitais e apontam para a urgência na superação dos velhos problemas do sistema educacional brasileiro, que requer a ampliação de políticas públicas educacionais, com ênfase na formação inicial e continuada dos professores a partir das realidades das instituições de ensino.

\section{O estudo do lugar de vivência no ensino de geografia}

Pensar na lógica dos lugares de vivência tem sido uma tarefa importante para a compreensão da dinâmica socioespacial a partir de outras dimensões escalares. E, nesse sentido, a Geografia Escolar assume papel relevante ao fazer uso de problematizações e ressignificações de temas e conteúdos que estão relacionados ao presente do nosso lugar de vivência, sejam sociais, políticos, ambientais ou econômicos.

Destacamos, por meio das discussões desenvolvidas neste texto, que o conhecimento geográfico escolar não decorre de uma evolução linear, mas se desenvolve nas relações dialéticas e contraditórias, considerando o saber acadêmico, escolar e as interações estabelecidas pela realidade. Assim, cabe perguntar: como as temáticas relacionadas ao espaço de vivência estão contempladas nas políticas educacionais, mais especificamente na Base Nacional Curricular Comum (BNCC)? Em uma simples consulta aos documentos publicados já podemos constatar que as diretrizes são amplas, e, quando se trata das sete "Competências Específicas de Geografia para o Ensino Fundamental", o que pode ser feito para contemplar os estudos geográficos a partir do lugar de vivência é a base que se apresenta no trabalho com os princípios geográficos, no intuito de ampliar a leitura de mundo e focar na formação da consciência espacial-cidadã. Tais questões têm perpassado as discussões e o texto final da Base Nacional Comum Curricular, conforme observamos em um de seus princípios destacado a seguir:

Desenvolver autonomia e senso crítico para compreensão e aplicação do raciocínio geográfico na análise da ocupação humana e produção do espaço, envolvendo os princípios de analogia, conexão, diferenciação, distribuição, extensão, localização e ordem. (BRASIL, 2018, p. 357).

Mais direcionado para nossa área de atuação e pesquisa, o documento referência em vigor no Brasil também menciona nas competências específicas de Geografia, para o ensino fundamental, a necessidade de desenvolver o pensamento "[...] espacial, fazendo uso das linguagens cartográficas e iconográficas, de diferentes gêneros textuais e das geotecnologias para a 
resolução de problemas que envolvam informações geográficas." (BRASIL, 2018, p. 364).

Logo, o processo educativo comprometido com a possibilidade de situar os alunos socialmente implica na compreensão da dinâmica da realidade em suas diferentes dimensões e contextos, incluindo o pertencimento ao seu lugar de vivência. Para isso, é importante:

\begin{abstract}
Utilizar as linguagens cartográfica, gráfica e iconográfica e diferentes gêneros textuais e tecnologias digitais de informação e comunicação no desenvolvimento do raciocínio espaço-temporal relacionado a localização, distância, direção, duração, simultaneidade, sucessão, ritmo e conexão. (BRASIL, 2018, p. 355).
\end{abstract}

Nesse contexto, temos muitos desafios e encaminhamentos de propostas para a efetivação de uma educação geográfica, levando-se em conta a realidade dos alunos e valorizando as linguagens e possibilidades disponíveis em cada contexto. Aliás, apesar das críticas, numa outra dimensão, à BNCC, consideramos que o referido documento ressalta por vezes o uso das diversas linguagens, dentre elas a cartográfica e as geotecnológicas.

Os eventos do cotidiano marcados pelas relações sociais estão carregados de diálogos e de contextos individuais e coletivos de diferentes modos de pensar. A compreensão das políticas educacionais precisa ser orientada por princípios que se relacionem com o lugar de vivência, o que, nesse caso, significa oportunizar uma educação geográfica de modo a evidenciar a relevância do estudo da dinâmica do lugar na construção de uma consciência social, econômica e política mais comprometida com a realidade, identificando as suas incoerências e conflitos dentro de determinados contextos. Assim, as reflexões geográficas a partir de situações contextualizadas possibilitam a formação de uma visão crítica do lugar de vivência, considerando os processos e ações que produzem os movimentos (avanços e recuos) característicos da sociedade contemporânea.

\title{
3. Os recursos tecnológicos/cartográficos na construção de temas, noções e conceitos geográficos do/no lugar
}

O uso das geotecnologias digitais está cada vez mais possível nos espaços escolares. Não queremos generalizar, muito menos desconsiderar os inúmeros fatores que limitam o ensino e a aprendizagem mediados por tais recursos, mas é possível afirmar que cada vez mais o uso e o acesso têm chegado no dia a dia e consequentemente nas práticas escolares.

Diante desse contexto, o avanço significativo de plataformas que possibilitam a geovisualização, bem como o surgimento das redes sociais, traz para a educação geográfica inúmeras possibilidades. Primeiro, destacamos que o simples uso e acesso cotidiano das tecnologias digitais e das redes sociais, per si, representam fenômenos geográficos, de modo que citamos um bem simples, que é o fenômeno da globalização. Por outro lado, podemos vislumbrar também possibilidades didático-pedagógicas dos usos no âmbito escolar, visto que significativa parte dos alunos possuem acesso à internet, ou mesmo smartphones. 
$\mathrm{Na}$ realidade, hoje temos diversas oportunidades para inovar o ensino de Geografia urbana. Desde os recursos tecnológicos que propiciam a análise dos fenômenos espaciais, como a ferramenta do Google Earth e outros aplicativos que subsidiam a visualização de dados e imagens importantes para a educação geográfica, até recursos como música, poesia, literatura, fotografias, filmes e atividades práticas de campo, que são fundamentais para aumentar o interesse dos alunos pela Geografia e envolvê-los com a construção do seu próprio conhecimento. (ARAÚJO, 2018, p. 98).

Trabalhando na perspectiva de conhecer as possibilidades que os recursos tecnológicos apresentam para o estudo da organização do espaço geográfico, é importante levar em consideração a realidade dos estudantes, o cenário das escolas (infraestrutura, formação docente) e o uso das Tecnologias Digitais da Informação e Comunicação (TDIC's) para a potencialização do ensino de Geografia na busca da compreensão das conexões e rupturas do espaço, pois, como destaca Castrogiovanni,

A escola faz parte do espaço geográfico, e como tal reflete as tensões e emoções da complexidade do conjunto de sistemas e objetos das ações que a compõe. É impossível a escola fora desta indissociabilidade. Por outro lado, este subespaço geográfico chamado de escola tem sido lido por muitos como sendo, somente, um ponto de encontro entre os sujeitos. (CASTROGIOVANNI, 2011, p. 62).

Assim, o trabalho escolar que viabilize a competência de analisar o espaço geográfico a partir de sua totalidade exige do professor a capacidade de articular teoria e prática, mas requer acima de tudo que apresente clareza nos conceitos básicos da Geografia e compreenda a sociedade e o espaço como resultantes da relação do homem com a natureza a partir de escalas e contextos diferentes. Castellar (2011, p. 129) destaca que a cartografia é necessária na educação geográfica, pois é "[...] considerada uma linguagem, um sistema de código de comunicação imprescindível em todas as esferas da aprendizagem em Geografia, articulando fatos, conceitos e sistemas conceituais que permitem ler e escrever as características do território."

Portanto, a inserção de diferentes linguagens no ensino torna-se potencializador desse processo, uma vez que "[...] o uso da linguagem cartográfica é essencial na formação dos sujeitos e possibilita compreender os fenômenos geográficos a partir de suas representações." (CAMPOS, 2017, p. 51). Mas é preciso incorporar nesses estudos o olhar e a investigação dos seus lugares de vivência, criando assim questionamentos e problematizações de suas conjunturas, capazes de colaborar com uma educação transformadora. Segundo Santos (2006, p. 116),

Uma das características marcantes do sistema atual, comparado com os anteriores, é a rapidez de sua difusão. As inovações técnicas introduzidas nos vinte anos após a segunda guerra mundial se espalharam duas vezes mais rapidamente do que aquelas introduzidas depois da primeira guerra mundial e três vezes mais do que as introduzidas entre 1890 e 1919.

Muitas discussões têm sido desenvolvidas nesse contexto, ainda mais que esse movimento intensivo da sociedade exige soluções técnicas e uma 
adequação constante das práticas no espaço escolar a partir de análises com críticas fundamentadas. De acordo com Santos (2006, p. 118),

[...] a tecnologia atual se impõe como praticamente inevitável. Essa inevitabilidade tanto se deve ao fato de que a sua difusão é comandada por uma mais-valia que opera no nível do mundo e opera em todos os lugares, direta ou indiretamente, quanto em razão da formidável força do imaginário correspondente (Gras \& PoirotDelpech, 1992), que facilita a sua inserção em toda parte.

Não podemos ignorar o fato de que este momento é marcado pelo aprisionamento da globalização, do avanço da técnica associado ao processo contraditório do desenvolvimento, da exclusão e da segregação das pessoas e dos espaços. Mas não podemos nos curvar diante desse movimento, como algo natural. Por isso o ambiente escolar pode fazer parte desse processo, sendo até indispensável uma prática que subsidie o olhar e o raciocínio com certa agilidade para acompanhar essas mudanças no seu lugar de vivência, o que representa um grande desafio, conforme aponta Santos (2006).

Diante do crescimento de pesquisas sobre o lugar de vivência, as discussões no âmbito da Geografia têm ganhado fôlego, mas ainda temos que refletir sobre quais estratégias de ensino associadas às novas tecnologias viabilizam a construção de aprendizagens significativas com a reinvenção pedagógica do docente, através de suas práxis política e educativa em diferentes tempos e espaços.

Para refletir acerca do ensino de Geografia a partir das TDIC's, levantamos o seguinte questionamento: para que e como ensinar Geografia a partir do lugar de vivência, na perspectiva da fluidez do tempo e do espaço? Sem dúvidas, é um grande desafio. Uma tarefa desafiadora no sentido de compreender a necessidade de professores capacitados, que saibam atrelar 0 conhecimento teórico e pedagógico, como também compreender os anseios e perspectivas dos alunos a partir da realidade em que estão inseridos.

Hoje, percebermos o número crescente e quase unificador de alunos que possuem aparelhos celular e/ou tablets, sujeitos que estão conectados em tempo real com as informações nas e das mais diversas escalas de análise. Sem dúvidas, não cabe mais nesse cenário aulas de Geografia que levem apenas informações, pois isso os alunos já levam para as salas de aula, em algumas situações ainda mais que os professores.

Assim, o papel do professor em Geografia deve consistir em desenvolver habilidades para aguçar a criticidade inerente às informações do/no lugar e do/no contexto em que estão inseridos, na perspectiva de dar conta de como fazer a leitura do seu cotidiano e de sua relação com o mundo.

Os alunos vivem uma rica experiência espacial, fragmentada é verdade, mas diversa, em função da globalização, da cultura midiática, da informática, em função de sua experiência em seu próprio lugar, mais diverso, com eventos espaciais diversos, que apresentam problemas ambientais, de trânsito, violência urbana, práticas de grupos, gangues, guetos, miséria na rua e outros. Como pensar a Geografia sem considerar isso? (CAVALCANTI, 2014, p. 95). 
Não há como desconsiderar as experiências que os alunos carregam de seu universo, é preciso potencializar o ensino de Geografia considerando as tensões, emoções e complexidade da sociedade. O estudo do lugar de vivência é importante e necessário para o estudante, na medida em que ele problematiza os aspectos que expressam as condições sociais, políticas, ambientais, culturais e econômicas de seu lugar. Após esse exercício, as possibilidades de compreensão de todos os elementos ali existentes são maiores na perspectiva da totalidade, considerada no seu conjunto, sem perder de vista a análise de outras escalas de observação.

Assim como os alunos, os professores e as escolas possuem hoje alguns instrumentos tecnológicos que podem auxiliar a prática docente direcionada à aprendizagem dos conceitos e categorias da Geografia a partir do seu lugar de vivência. Novas e velhas tecnologias da informação e comunicação estão disponíveis e podem servir como uma ferramenta pedagógica eficiente. No entanto, precisamos destacar que o uso de determinadas tecnologias não pode ser considerado sinônimo de uma aula interativa e inovadora, pelo contrário, caso não sejam usadas de formas atrativas e efetivas, pode-se perder 0 objetivo pedagógico, tornando-se uma prática obsoleta.

Compreendemos como práticas atrativas e efetivas as ações direcionadas ao ensino de Geografia que consigam atrair a atenção dos alunos para as situações de aprendizagem propostas, construindo as habilidades necessárias para perceber, analisar e atuar no lugar a partir das ações cotidianas em que os sujeitos são colocados diariamente.

É importante destacar que, muitas vezes, o distanciamento entre o sujeito e o conteúdo (conceitos, categorias e demais questões que envolvem o objeto de estudo da Geografia) gera o desinteresse pela compreensão, tornando, assim, o aprendizado sem significado, não sendo, portanto, efetivado o objetivo de ensinar/aprender a Geografia.

Ainda assim, apesar de inúmeras controvérsias que perpassam o ambiente escolar e fazem parte dos debates em torno das novas e velhas tecnologias na educação e no ensino, precisamos considerar que é uma realidade que não pode ser passada despercebida pelos professores. Destacamos o docente não por compreender que ele seja o único responsável em inserir e ou (re)significar suas aulas, mas por saber que a falta de incentivo pelos poderes, situação que afeta as gestões, acaba muitas vezes afastando essas possibilidades de ressignificação das práticas pedagógicas no cenário escolar, constituindo assim um grande problema que perpassa o ensino-aprendizagem. Nesse contexto,

Muitas dificuldades enfrentadas no dia a dia do professor de Geografia podem ser superadas com o uso das TICs. Trabalhar alguns conteúdos geográficos sem ter a imagem, a representação do real dificulta a compreensão do aluno e consequentemente o ensinoaprendizagem. (SANTOS, 2015, p. 173).

Tais dificuldades, que são inúmeras, podem ser elencadas como obstáculos para o uso das TDIC's nas aulas de Geografia. Inicialmente destacamos a falta de formação, inicial e continuada, objetivando preparar os professores para tal 
situação, em que muitas vezes acontece a autoformação com os que possuem mais habilidades e familiaridade com as tecnologias. Santos (2015, p. 172) destaca que

A aplicação das Tecnologias da Informação e Comunicação - TICs no ensino é considerada um desafio para os professores, principalmente para aqueles que tiveram uma formação tradicional (livro, quadro e caderno), e isto gera resistência por parte da parcela destes profissionais, talvez por não possuírem as técnicas necessárias de manuseio destas ferramentas.

A ideia é, então, fazer a ampliação do processo formativo para instrumentalizar os professores a fazerem uso no exercício da atuação docente de diferentes ferramentas e linguagens para vencer os obstáculos relacionados, até mesmo, às imposições do próprio cotidiano escolar.

\title{
4. Uma proposta didático-pedagógica para o estudo do lugar de vivência a partir do uso do "Instagram" e/ou outras linguagens
}

Hoje, mais que nunca, é comum observarmos a contribuição das tecnologias digitais da informação e comunicação nas práticas educativas, e na Geografia revela-se nitidamente abrindo inúmeras possibilidades. Não obstante, o avanço das técnicas e das tecnologias contribuíram significativamente para as possibilidades de análise do/no espaço, do conhecimento, da ciência e da realidade. Aliás, essas possibilidades nos direcionam a inúmeras questões, que podem ser associadas ao processo educativo.

Milton Santos nos provocou, em sua obra Por uma outra globalização: do pensamento único à consciência universal (2013), ao afirmar que vivemos num mundo confuso e confusamente percebido. De fato, esse novo momento vivido, que não está restrito especificamente ao objeto de estudo da ciência geográfica, aponta um novo olhar para o conhecimento e o ensino. Percebemos que muitas dessas confusões, que podemos também denominar como possibilidades, são resultados do processo de evolução das tecnologias e ao mesmo tempo das desigualdades de acesso pela sociedade, nos mais diversos campos, que possibilitam os fluxos e a fluidez.

\begin{abstract}
De fato, se desejamos escapar a crença de que esse mundo assim apresentado é verdadeiro, e não queremos admitir a permanência de sua percepção enganosa, devemos considerar a existência de pelo menos três mundo num só. O primeiro seria o mundo tal como nos fazem vê-lo: a globalização como fábula; o segundo seria o mundo tal como ele é: a globalização como perversidade; e o terceiro, o mundo como pode ser: uma outra globalização. (SANTOS, 2013, p. 18).
\end{abstract}

Nessa perspectiva, na linha de pensamento de Milton Santos, acreditamos ser o uso das tecnologias digitais da informação e comunicação também fábula, perversidade, mas sobretudo possibilidade. Apesar dos ligeiros avanços e pseudodemocratização do uso e acesso, compreendemos que perversamente nem todos os alunos e alunas, sobretudo das escolas públicas brasileiras, possuem tais dispositivos.

Assim, ao desenvolvermos esta proposta, destacamos a necessidade de planejamento prévio, bem como conhecimento da realidade educacional para a 
percepção da viabilidade de tal atividade. Dessa forma, o objetivo da proposição é conhecer as múltiplas dimensões e noções geográficas do lugar de vivência a partir da linguagem cartográfica e da rede social "Instagram"; perceber o potencial da linguagem cartográfica para o estudo do lugar; e, utilizar a rede social "Instagram" como um dispositivo de aprendizagem. Vale ressaltar que, no decorrer do trabalho, os professores poderão ajustar suas propostas às demandas do lugar de vivência com o intuito de potencializar a interatividade e criatividade dos estudantes a partir da autoria de materiais diversos e da possibilidade de trilhar caminhos para avançar na elaboração de um conhecimento crítico da realidade. Para o desenvolvimento da presente proposta são necessárias algumas ações prévias, conforme detalhadas a seguir:

1 Acesso ao site do IBGE Cidades: https://cidades.ibge.gov.br/. O município escolhido foi Serrolândia, na Bahia (Figura 1). Assim, selecionamos mapas, infográficos e pirâmide etária. Há muitas informações, o que requer a seleção prévia, de acordo com a demanda.

\section{Figura 1 - Localização do município de Serrolândia no contexto do Estado da Bahia}

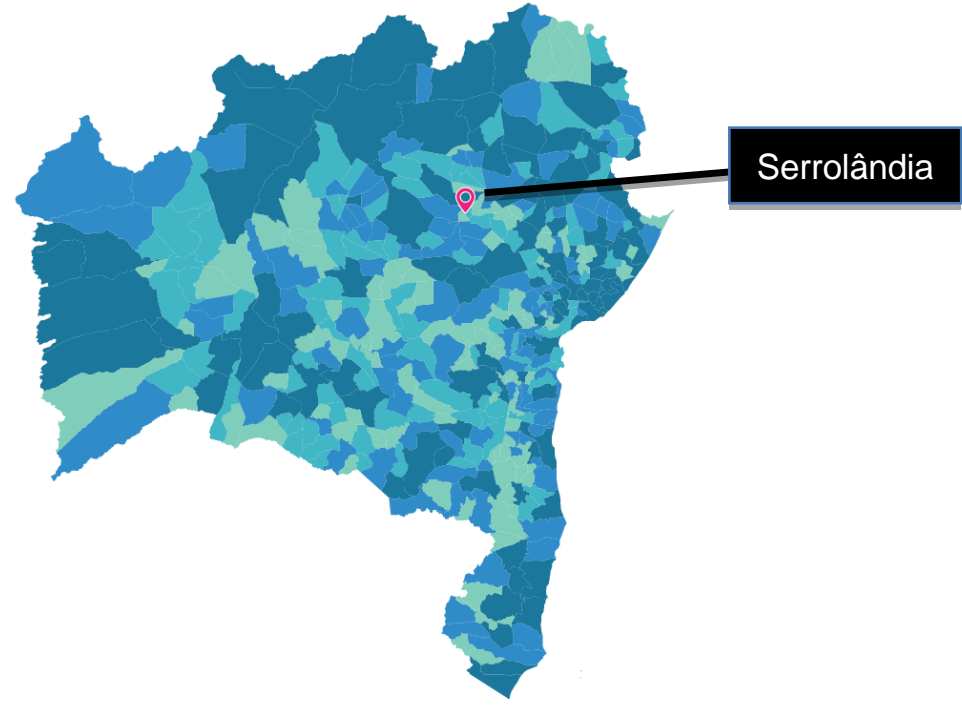

Fonte: https://cidades.ibge.gov.br/. Elaboração dos autores

O município de Serrolândia localiza-se no centro norte do Estado da Bahia, no Território de Identidade do Piemonte da Diamantina, com população estimada de 13.347 pessoas. Desenvolve atividades agropecuárias, mas o destaque principal no contexto regional centra-se no grande número de indústrias de bolsas, com geração de emprego e renda. A Figura 2 apresenta um dado relevante sobre a situação do município quanto ao esgotamento sanitário adequado, sendo necessária a atenção dos representantes públicos para atender às demandas da sociedade local. 
Figura 2 - Esgotamento sanitário adequado no município de Serrolândia, Bahia

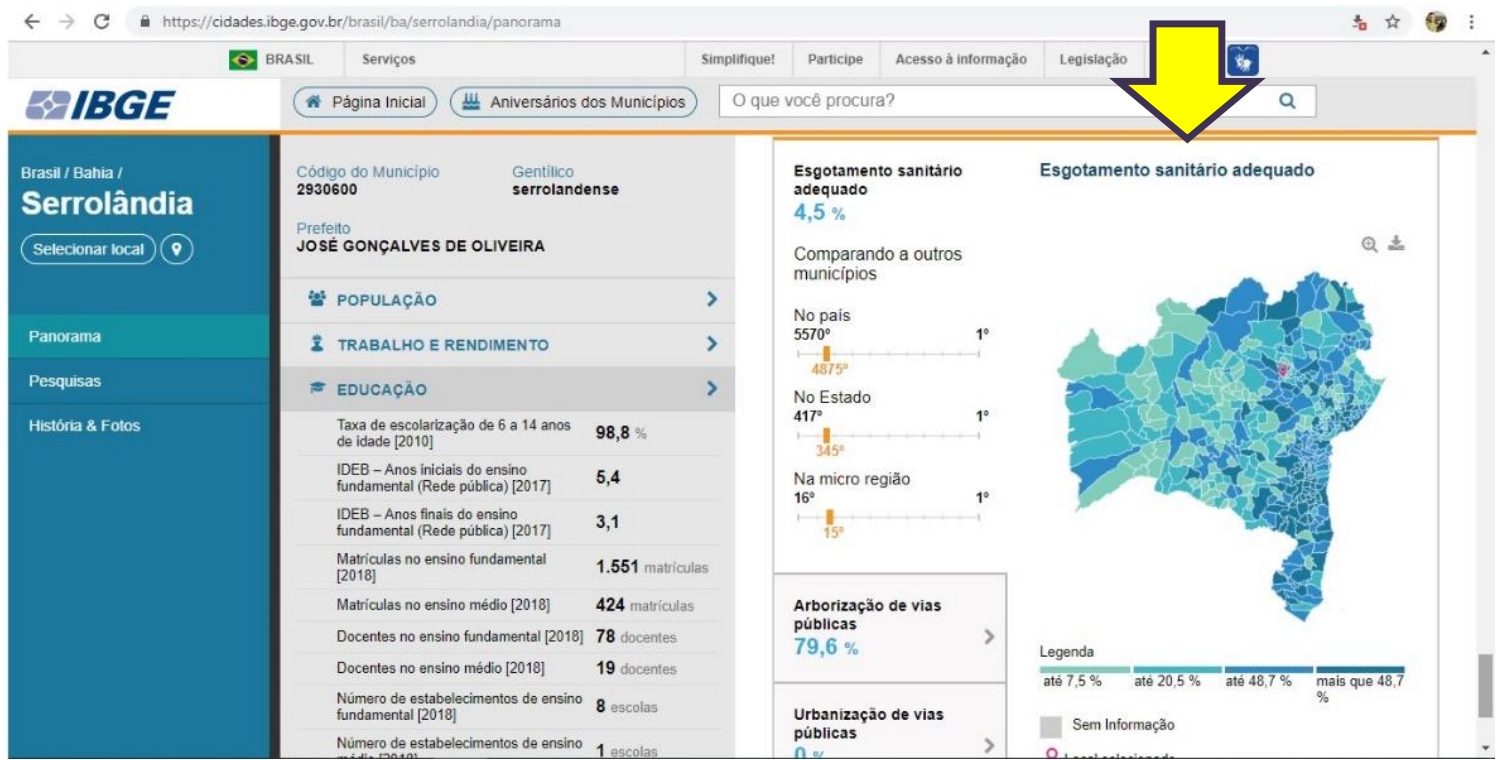

Fonte: https://cidades.ibge.gov.br/. Elaboração dos autores

A abordagem sobre as condições do esgotamento sanitário na sala de aula permite que os estudantes avaliem as políticas públicas aplicadas na infraesturura do município e estabeleçam uma relação com outras variáveis importantes para a qualidade de vida dos moradores.

O estudo do PIB per capita (Figura 3) também representa um dado importante para o estabelecimento da reflexão e tradução dos indicadores que representam o desenvolvimento socioeconômico do município. Apesar de suas limitações, é importante conhecer sua representação e associá-lo a outras realidades e escalas.

Figura 3 - PIB per capita do município de Serrolândia, Bahia

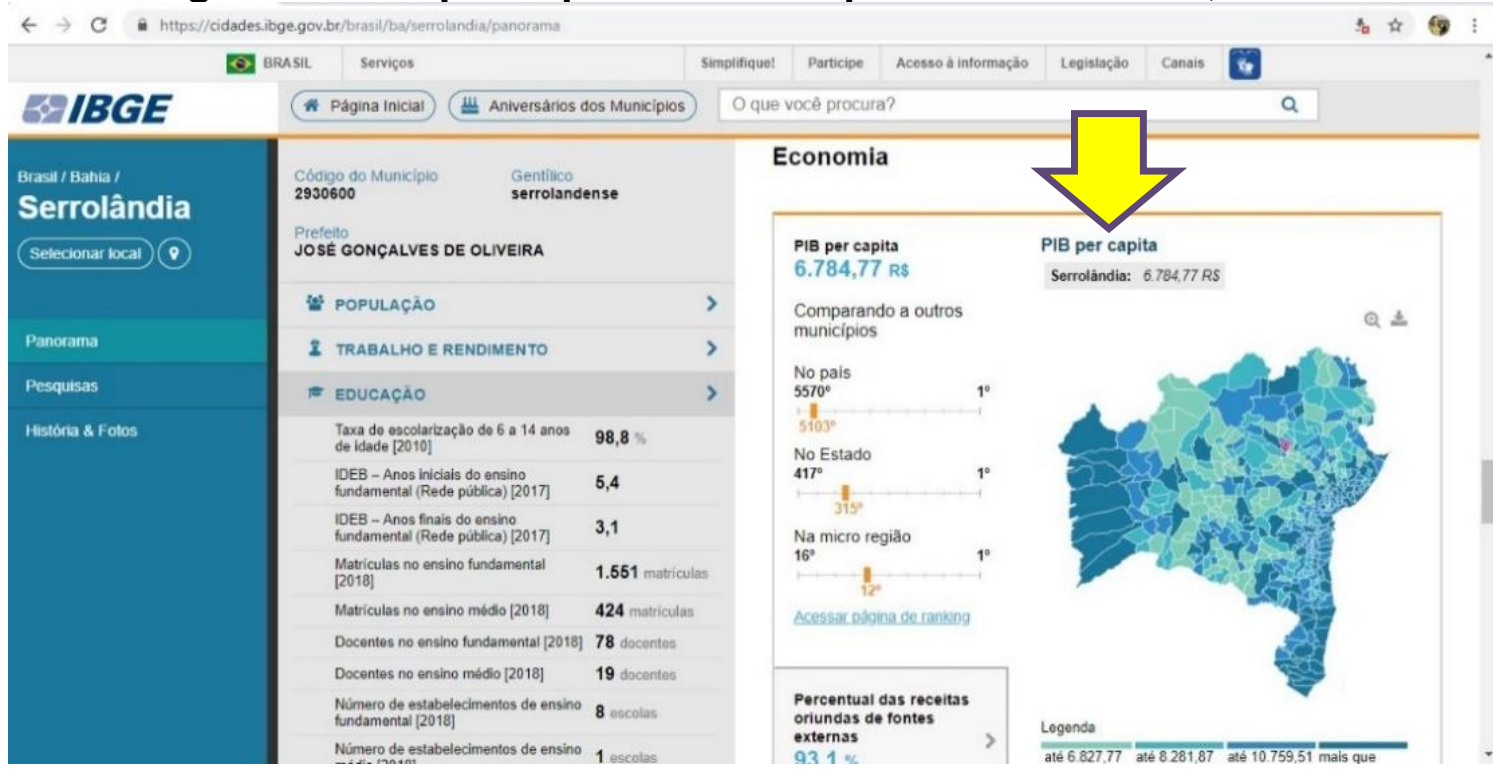

Fonte: https://cidades.ibge.gov.br/. Elaboração dos autores 
A reflexão sobre a média salarial dos trabalhadores formais (Figura 4) tornase relevante para a compreensão da dinâmica do lugar a partir das variedades de aspectos que compõem o campo social e que demandam, portanto, a atenção da sociedade e dos grupos políticos e particulares, que também são responsáveis pelas questões concernentes ao campo social debatidas na atualidade. A noção do salário médio mensal dos trabalhadores formais do município pode ser um indicador importante para a compreensão dos arranjos espaciais, assim como para o planejamento em curto e longo prazos, no sentido de estabelecer políticas para a manutenção da força do lugar mediante as crises próprias à realidade, caracterizadas pela dinâmica do espaço geográfico frente à complexidade e exigência do mundo contemporâneo.

\section{Figura 4 - Salário médio mensal dos trabalhadores formais do município} de Serrolândia, Bahia

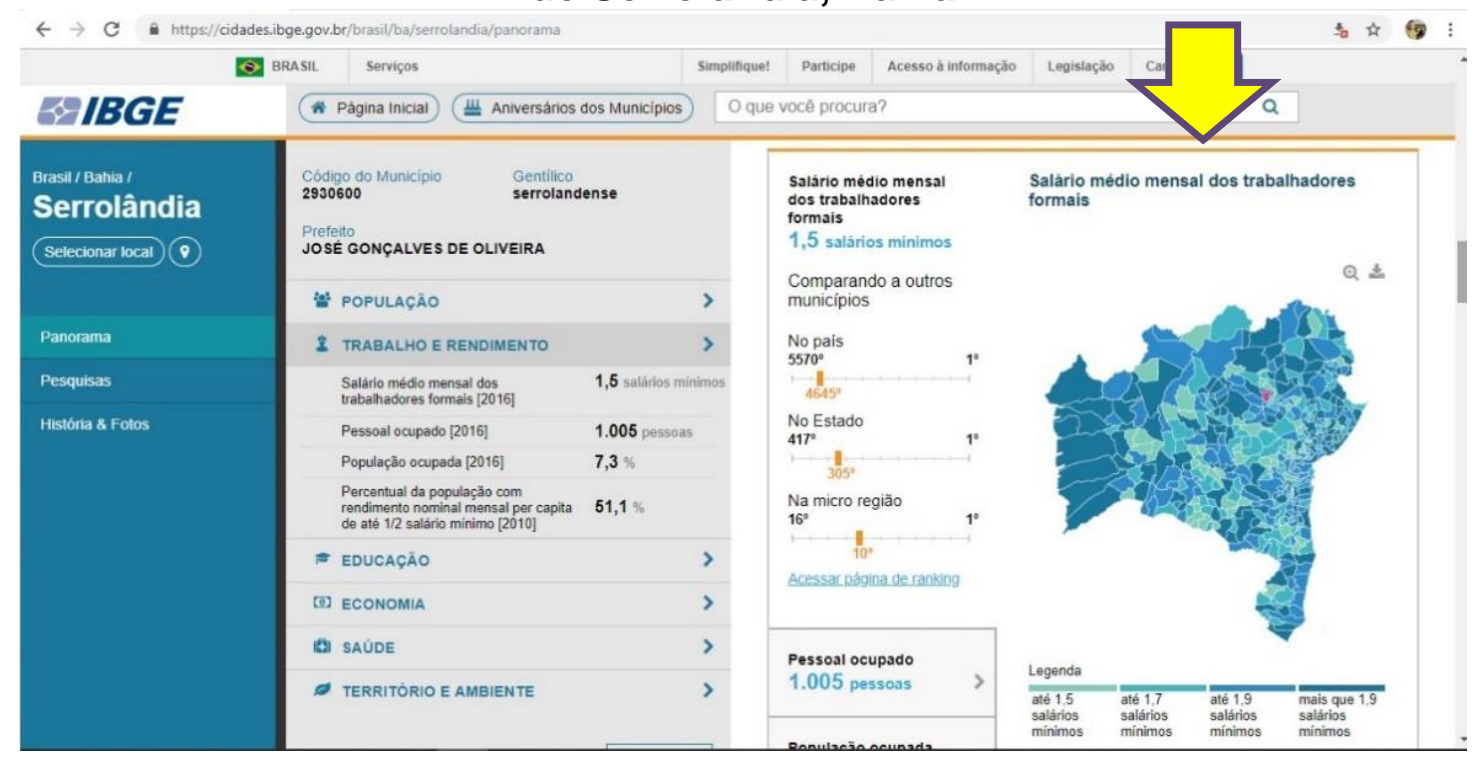

Fonte: https://cidades.ibge.gov.br/. Elaboração dos autores

A representação de dados referentes à população (Figura 5), tema recorrente das aulas de Geografia, também pode ser uma abertura para as discussões e aprofundamentos das questões da população local. Nesse sentido, torna-se imprescindível um trabalho que retome os dados censitários do IBGE de pesquisas anteriores para entender a dinâmica e tendência do município, procurando fazer uma relação com outros fatores.

Tratar desse tema na escola é uma excelente oportunidade para desenvolver uma proposta interdisciplinar de ensino ao promover a aproximação com outras questões, como o processo de desmembramento e emancipação e a sua influência na dinâmica populacional no município de Serrolândia. 


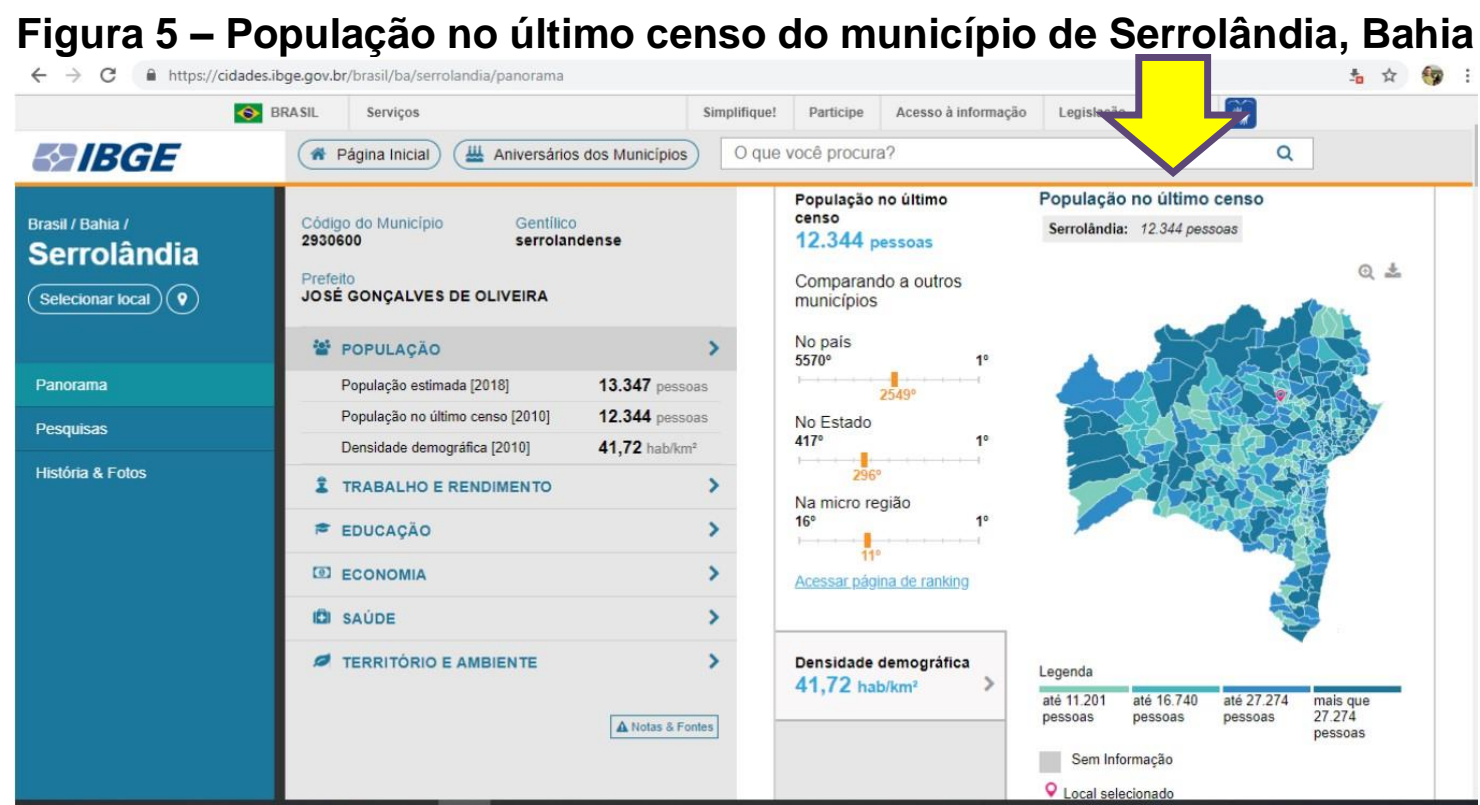

Fonte: https://cidades.ibge.gov.br/. Elaboração dos autores

Ainda em relação ao estudo da população, pode ser desenvolvida uma pesquisa multitemporal com destaque para os dados da mortalidade infantil (Figura 6), a fim de analisar o crescimento vegetativo do município e tecer outras análises mais conclusivas sobre o tema.

\section{Figura 6 - Mortalidade do município de Serrolândia, Bahia}

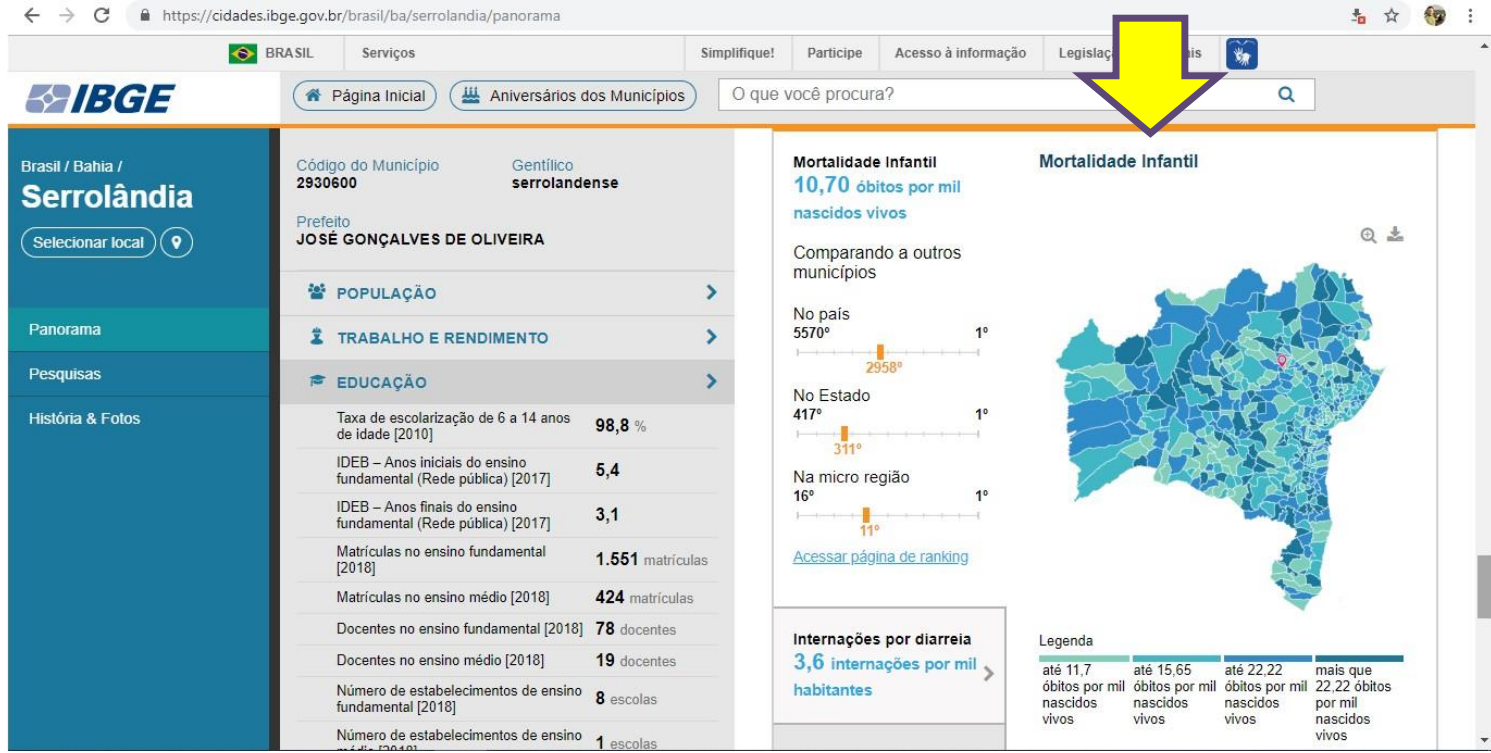

Fonte: https://cidades.ibge.gov.br/. Elaboração dos autores

Essas possibilidades de trabalhos a partir de representações gráficas e cartográficas do lugar de vivência representam o potencial da Geografia no estabelecimento do diálogo e aproximação da escola com a realidade. Como afirma Nunes et al (2018, p. 25), "[...] é grande o desafio que o ensino, como prática social, coloca aos professores no cotidiano, já que pensar a prática pedagógica requer analisar o contexto histórico, social e econômico vigente." Uma ação pedagógica associada à realidade dos estudantes revela um compromisso social, ao mesmo tempo em que assume a autonomia do ensino. 
2 Com o levantamento das informações, ao optar pelo uso da rede social Instagram (Figura 7), é necessário criar perfil. Após criação do perfil, o mesmo deve ser divulgado para que os alunos e comunidade possam seguir e interagir. O Instagram atualmente possui algumas funções que são extremamente propícias para fins didáticos, como, por exemplo: enquetes e ambiente para perguntas e respostas. Caso não seja possível o uso da rede social, sugere-se a utilização de outras estratégias, como a elaboração de cartazes impressos ou slides associados ao jogo quiz.

\section{Figura 7 - Funções do Instagram que possibilitam a interação e construção de propostas didático-pedagógicas}

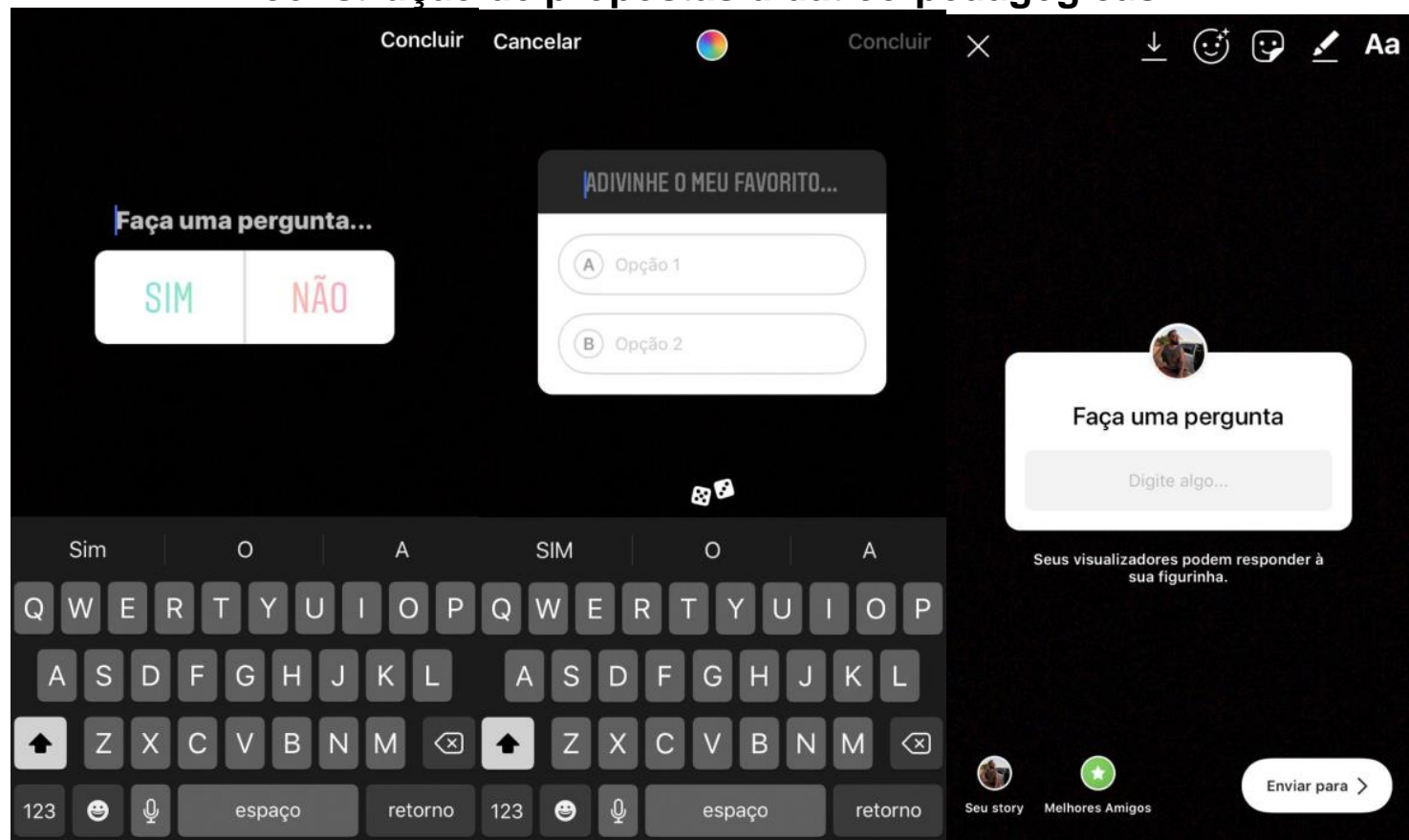

Fonte: https://www.instagram.com/?hl=pt-br. Organização/Montagem dos autores

3 Elaboração de regras e orientações para os alunos. As regras podem ser estabelecidas a partir de cada realidade

4 Planejamento da proposta avaliativa. O processo de avaliação sugerido tem como parâmetro a participação dos alunos nas aulas e postagens (discussões, inferências, estabelecimento de relação entre as temáticas discutidas), bem como exposições na "roda de conversa".

Após as "ações prévias", a sugestão é desenvolver as atividades, conforme orientações no Quadro 1:

Quadro 1 - Conhecendo meu lugar de vivência CONHECENDO O MEU LUGAR DE VIVÊNCIA

\begin{tabular}{|c|c|l|}
\hline \multicolumn{3}{|c|}{ CONHECENDO O MEU LUGAR DE VIVÊNCIA } \\
\hline Momento & Duração & Atividade a ser desenvolvida \\
\hline $1^{\text {10 Momento }}$ & 1 semana & $\begin{array}{l}\text { Proposta 01 - Com uso do Instagram: } \\
\text { Apresentação da proposta. Estudo do } \\
\text { mapa e seus elementos. (As postagens } \\
\text { serão a partir dos mapas e infográficos }\end{array}$ \\
\hline
\end{tabular}

Para0nde!?, Porto Alegre, v.13, n.1, p. 59-76, 2020. http://seer.ufrgs.br/paraonde 


\begin{tabular}{|c|c|c|}
\hline & & $\begin{array}{l}\text { disponíveis no site do IBGE. Dessa } \\
\text { forma, é imprescindível debater o mapa } \\
\text { e seus elementos para, então, explorar } \\
\text { a referida linguagem); } \\
\text { Proposta } 02 \text { - Sem o uso do Instagram: } \\
\text { Apresentação da proposta. Estudo do } \\
\text { mapa e seus elementos. (Poderão ser } \\
\text { feitos cartazes impressos, slides ou } \\
\text { mesmo a visita interativa para } \\
\text { conhecimento dos mapas e infográficos } \\
\text { disponíveis no site do IBGE. É } \\
\text { imprescindível debater o mapa e seus } \\
\text { elementos para, então, explorar a } \\
\text { linguagem escolhida). }\end{array}$ \\
\hline $2^{\circ}$ Momento & 1 semana & $\begin{array}{l}\text { Proposta 01- Com uso do Instagram: } \\
\text { Postagens no Instagram para interação. } \\
\text { (Esta etapa é de um quadro } \\
\text { denominado "Você sabia?", nele, no } \\
\text { decorrer da semana, o perfil postará } \\
\text { informações diversas, curiosidades } \\
\text { sobre o município de Serrolândia-BA, } \\
\text { utilizando a opção enquete, disponível } \\
\text { no aplicativo. O objetivo é despertar a } \\
\text { curiosidade e envolvimento dos } \\
\text { estudantes); } \\
\text { Proposta 02 - Sem o uso do Instagram: } \\
\text { Elaboração/montagem de cartazes } \\
\text { impressos, slides, ou mesmo visita } \\
\text { interativa ao site. (Esta etapa é de um } \\
\text { quadro denominado "Você sabia?", } \\
\text { nele, constará informações diversas, } \\
\text { curiosidades sobre o município de } \\
\text { Serrolândia - BA, sugere-se a } \\
\text { utilização de jogo tipo quiz. O objetivo é } \\
\text { despertar a curiosidade e envolvimento } \\
\text { dos estudantes). }\end{array}$ \\
\hline 2o Momento & 3 semanas & $\begin{array}{l}\text { Proposta } 01 \text { - Com uso do Instagram: } \\
\text { Postagens interativas dos mapas sobre } \\
\text { população, trabalho e rendimento, } \\
\text { educação, saúde, economia, território e } \\
\text { ambiente. (Nesta etapa, em sala de } \\
\text { aula serão previamente iniciadas as } \\
\text { discussões, sendo seguidas das } \\
\text { interações a partir das postagens no } \\
\text { perfil do Instagram, que ocorrerão no } \\
\text { decorrer da semana. Podem ser } \\
\text { lançadas questões para pesquisa e } \\
\text { resposta, bem como a utilização da } \\
\text { opção enquetes; } \\
\text { Proposta 02 - Sem o uso do Instagram: } \\
\text { Elaboração/montagem de cartazes } \\
\text { impressos, slides ou mesmo visita }\end{array}$ \\
\hline
\end{tabular}




\begin{tabular}{|c|c|c|}
\hline & & $\begin{array}{l}\text { interativa ao site para conhecimento } \\
\text { dos mapas sobre população, trabalho e } \\
\text { rendimento, educação, saúde, } \\
\text { economia, território e ambiente. (Nesta } \\
\text { etapa, em sala de aula serão } \\
\text { previamente iniciadas as discussões, } \\
\text { sendo seguidas das interações, } \\
\text { podendo novamente utilizar a estratégia } \\
\text { do jogo quiz). }\end{array}$ \\
\hline $4^{\circ}$ Momento & 1 semana & $\begin{array}{l}\text { Proposta } 01 \text { - Com uso do Instagram: } \\
\text { Roda de conversa "Eu conheço meu } \\
\text { lugar de vivência?". Este espaço é } \\
\text { destinado para debater temas diversos } \\
\text { vinculados às postagens, bem como } \\
\text { para avaliação da eficácia da } \\
\text { estratégia. } \\
\text { Proposta } 02 \text { - Sem o uso do Instagram: } \\
\text { Roda de conversa "Eu conheço meu } \\
\text { lugar de vivência?". Este espaço é } \\
\text { destinado para debater temas diversos } \\
\text { vinculados às atividades desenvolvidas, } \\
\text { bem como para avaliação da eficácia } \\
\text { da estratégia. }\end{array}$ \\
\hline
\end{tabular}

Fonte: Elaboração dos autores

A sequência didática apresentada acima foi planejada para ser desenvolvida em seis semanas, podendo ser ajustada de acordo com a realidade e especificidades de cada planejamento. Como desejamos a utilização da linguagem cartográfica atrelada ao Instagram e/ou outras lingagens, sugerimos que no primeiro momento seja feita uma abordagem do mapa e seus elementos, para então estudar os conceitos geográficos pelo mapa, não como o fim, mas como o início do processo.

É importante destacar que construímos tal proposta direcionando as atividades à rede social "Instagram". No entanto, as possibilidades para associação às demais redes e/ou outras linguagens são inúmeras, conforme apresentamos no Quadro 1. O site IBGE Cidades dispõe de um acervo muito interessante que pode subsidiar as práticas pedagógicas para o estudo de diversos temas e expressões geográficas. E mais, para o estudo do lugar de vivência, a partir de temas diversos, as possibilidades disponibilizadas no site são extremamente apropriadas, por ser um material de fácil acesso com potencial explicativo da realidade a partir de informações relevantes que perpassam as condições socioeconômicas e ambientais do lugar, suas políticas e até suas contradições.

\section{Considerações finais}

A proposta de inserção do estudo do lugar de vivência a partir da linguagem cartográfica, da rede social "Instagram" e/ou outras linguagens no espaço 
escolar é amplamente divulgada e pode ser embasada por diversos discursos teóricos. Mesmo assim, ainda temos muitas limitações associadas ao funcionamento do próprio sistema de ensino vigente no nosso país, seja da estrutura ou da formação dos professores.

Precisamos ainda considerar que as transformações no espaço geográfico a partir das inovações tecnológicas ocorrem de forma veloz e contundente, exigindo uma adequação dos elementos didáticos para se fazer a análise geográfica, considerando os referenciais teóricos e metodológicos essenciais no ensino de Geografia.

Também, destacamos a manutenção e acesso aos instrumentos disponíveis nas escolas, pois são elevadíssimos os índices de escolas com laboratórios de informática desativados por falta de manutenção, por exemplo. São inúmeros os fatores que poderiam ser elencados aqui, mas finalizaremos com uma dificuldade central, que é o uso das velhas e novas tecnologias para a análise espacial, em que aulas genéricas e com outras perspectivas são desenvolvidas em detrimento da análise geográfica do lugar de vivência.

Há um problema de método e metodologia presente nas aulas de Geografia, que é gerado desde a formação inicial e que acompanha a prática docente. Muitas análises são feitas sem levar em conta as especificidades da ciência em questão. Contudo, a educação geográfica tem potencial para o entendimento dos processos que contribuem para a produção e estruturação do espaço social. O que trouxemos à tona ainda não aplicamos em sala de aula, é apenas um exemplo de como aprofundar os estudos sobre o lugar de vivência a partir da linguagem cartográfica atrelada à rede social "Instagram". Mencionamos que a presente proposição surgiu no âmbito do componente curricular Cartografia escolar e geotecnologias no ensino de Geografia, do Programa de Pós-Graduação em Geografia, Linha 02 - Cartografia e Cartografia escolar, da Universidade Estadual Paulista Júlio de Mesquita Filho (Unesp), Campus de Rio Claro.

Dessa forma, a partir das reflexões teóricas e críticas desenvolvidas neste trabalho, podemos fazer algumas considerações que não são necessariamente conclusões. As TDIC'S são importantes para o ensino de Geografia, mas não é apenas a sua utilização que possibilitará as análises geográficas, é necessário o domínio de habilidades técnicas e conceituais.

Uma outra questão que pode ser levantada é que o uso das novas tecnologias da informação e comunicação precisam estar além do uso pedagógico, pois não basta apenas utilizar tais recursos nas aulas, precisam ser utilizados para auxiliar na compreensão dos conteúdos, conceitos e situações que envolvem a Geografia, componente curricular abordado neste trabalho.

Portanto, para que as TDIC's sejam utilizadas em favor da prática docente, acreditamos que, além da democratização do acesso e uso de tais instrumentos, é imprescindível que haja a ampliação de políticas públicas educacionais de formação inicial e continuada dos professores, mas uma formação que seja efetivamente construída a partir das realidades das escolas, públicas ou privadas, que compõem o sistema educacional brasileiro. 


\section{Referências}

ARAÚJO, Joseane Gomes de. Abordagens do espaço urbano no ensino da Geografia. In: NUNES, Marcone Denys dos Reis et al. (Orgs.). Geografia e Ensino: aspectos contemporâneos da prática e da formação docente. Salvador: Eduneb, 2018. p. 95-108.

BRASIL. Base Nacional Comum Curricular: Educação é a Base. Ensino Médio. Brasília, DF: Ministério da Educação, 2018.

CAMPOS, Laís Rodrigues. Ensinar o espaço geográfico e o território com o uso da cartografia social. In: DENIS, Richter; CAMPOS, Laís Rodrigues. (Orgs.). Cartografia escolar. Goiânia: Editora Espaço Acadêmico, 2017. p. 51-60.

CASTELLAR, Sônia Vanzella. A cartografia e a construção do conhecimento em contexto escolar. In: ALMEIDA, Rosângela Doin. (Org.). Novos rumos da cartografia escolar: Currículo, linguagem e tecnologia. São Paulo: Contexto, 2011. p. 121-136.

CASTROGIOVANNI, Antônio Carlos. Espaço geográfico escola e seus arredores - descobertas e aprendizagens. In: CALLAI, Helena Copetti. Educação Geográfica: reflexão e prática. Ijuí: Ed. Inujuí, 2011. p. 61-74.

CAVALCANTI, Lana de Souza. A Geografia escolar e a sociedade brasileira contemporânea. In: TONINI, Ivaine Maria et al. (Orgs.). O ensino de Geografia e suas composições curriculares. Porto Alegre: Mediação, 2014. p. 77-98.

FREIRE, Paulo. Pedagogia da autonomia: saberes necessários à prática educativa. 52 ed. Rio de Janeiro: Paz e Terra, 2015.

NUNES, Marcone Denys dos Reis et al. Ensino de Geografia: vários contextos e diferentes linguagens para a prática pedagógica. In: NUNES, Marcone Denys dos Reis et al. (Orgs.). Geografia e Ensino: aspectos contemporâneos da prática e da formação docente. Salvador: Eduneb, 2018. p. 25-44.

SANTOS, Maria Francineila Pinheiros dos et al. O facebook no ensino de Geografia: desafios e possibilidades. In: SACRAMENTO, Ana Claudia Ramos et al. (Orgs.). Ensino de Geografia: produção o espaço e processos formativos. Rio de Janeiro: Consequência, 2015. p. 171-182.

SANTOS, Milton. A Natureza do Espaço: Técnica e Tempo, Razão e Emoção. 4 ed. São Paulo: Editora da Universidade de São Paulo, 2006.

Por uma outra globalização: do pensamento único à consciência universal. 23 ed. Rio de Janeiro: Record, 2013.

Nota:

Pesquisa financiada pela agência de fomento CAPES (Coordenação de Aperfeiçoamento de Pessoal de Nível Superior), a partir do Programa de Pós-Graduação em Geografia da Universidade Estadual Paulista Júlio de Mesquita Filho - UNESP/Rio Cla 